\title{
CULTURA: AUTÊNTICA E ESPÚRIA
}

Tradução de José Reginaldo Gonçalves

e Markus Hediger

\section{AS VARIÁVEIS CONCEPÇÕES DE CULTURA}

Há certos termos que possuem uma propriedade peculiar. Ostensivamente, eles demarcam conceitos específicos, conceitos que reivindicam uma validade rigorosamente objetiva. Na prática, eles rotulam áreas de pensamento indefinidas, que se deslocam, restringem-se ou ampliam-se de acordo com o ponto de vista daquele que os utiliza, abarcando em sua gama de significados concepções que não só não se harmonizam, mas são, em parte, contraditórias.

Uma análise de tais termos rapidamente revela o fato de que, sob esse choque de conteúdos variáveis, há uma percepção sensível totalizante. O que torna possível que um conjunto tão discordante de concepções atenda ao mesmo apelo é, precisamente, esse halo relativamente constante que as envolve. Assim, o que é "crime" para um, é "nobreza" para outro, mas ambos concordam que crime, seja lá o que for, é uma categoria indesejável, e que nobreza, seja lá o que for, é uma categoria apreciável. Da mesma forma, um termo como arte pode ser empregado de forma a significar coisas diversas, mas, seja lá o que signifique, o termo em si exige uma atenção respeitosa e normalmente invoca um estado mental agradavelmente refinado, uma expectativa de elevadas satisfações. Se a concepção específica de arte proposta ou implícita em uma obra de arte não nos agrada, não expressamos nossa insatisfação dizendo: "Então não gosto de arte." Afirmamos algo assim apenas quando nos encontramos numa atitude mental destrutiva. Normalmente, contornamos essa dificuldade dizendo: "Mas isso não é arte, é apenas algo convencional e agradável", ou: "Isso é puro sentimentalismo", ou: "Isso nada mais é do que experiência bruta, 
material para a arte, mas não é arte." Discordamos quanto aos valores das coisas e às relações das coisas, mas frequentemente concordamos no que diz respeito ao valor específico de um rótulo. É somente quando surge a pergunta quanto a onde precisamente colocar esse rótulo que os problemas começam. Esses rótulos - ou talvez fosse melhor chamá-los de tronos desocupados - são inimigos da humanidade, embora não tenhamos outra opção senão fazer as pazes com eles. Fazemos isso assentando neles nossos pretendentes favoritos. Os pretendentes rivais lutam até a morte; os tronos aos quais eles aspiram permanencem serenos, esplêndidos em seu ouro.

Pretendo defender as reivindicações de um pretendente ao trono chamado "cultura". Seja lá o que for, sabemos que cultura é, ou é considerada ser, uma coisa boa. Proponho apresentar a minha ideia do tipo de coisa boa que a cultura é.

O termo "cultura" parece ser usado em três sentidos ou grupos de sentido principais. Primeiramente, a cultura é usada de forma técnica pelos etnólogos e historiadores da cultura para dar forma a qualquer item socialmente herdado, material ou imaterial, no curso da vida humana. Assim definida, a cultura coincide com o próprio homem, uma vez que, mesmo os selvagens em níveis mais inferiores vivem em um mundo social caracterizado por uma teia complexa de hábitos, usos e atitudes tradicionalmente conservados. O método de caça dos boxímanes da África do Sul, a crença dos indígenas norte-americanos em "medicina", o tipo de drama trágico da Atenas de Péricles e o dínamo elétrico do industrialismo moderno são todos, igual e indiferentemente, itens de cultura, cada um deles sendo o produto do esforço espiritual coletivo do homem, cada um deles sendo preservado por um determinado período de tempo, não como resultado direto e automático de qualidades puramente hereditárias, mas por meio de processos imitativos mais ou menos conscientes resumidos por termos como "tradição" e "herança social". Desse ponto de vista, todos os seres humanos ou, de qualquer forma, todos os grupos humanos são cultos, ainda que de maneiras e graus de complexidade vastamente diferenciados. Para o etnólogo, existem muitos tipos de cultura e uma variedade infinita de itens culturais, mas nenhum valor, no sentido comum da palavra, lhes é atribuído. O uso que faz de palavras como "superior" ou "inferior", se é que ele as emprega alguma vez, não se refere a uma escala moral de valores, mas a estágios reais ou supostos em uma progressão histórica ou num esquema evolucionário. Não pretendo usar o termo "cultura" nesse sentido técnico. "Civilização" seria um substituto adequado para ele, caso não fosse o emprego usual desse termo mais voltado às formas mais complexas e sofisticadas do fluxo cultural. Para evitar confusão com outros usos da palavra "cultura", usos que envolvem enfaticamente a aplicação de uma escala de valores, usarei, onde for necessário, "civilização" no lugar da "cultura" dos etnólogos. 
O segundo emprego do termo é mais comum. Ele se refere preferencialmente a um ideal convencional de refinamento individual, baseado numa certa medida de conhecimento assimilado e experiência, mas que consiste principalmente de um conjunto de reações típicas sancionadas por uma classe e por uma tradição há muito estabelecida. Exige-se do candidato ao título de "pessoa culta" sofisticação no campo dos bens intelectuais, mas apenas até certo ponto. Muito mais ênfase é dada às maneiras, a certo refinamento de conduta, que assume diferentes tonalidades, de acordo com a natureza da personalidade que assimilou o ideal "culto". No pior dos casos, o refinamento degenera e assume a forma de um distanciamento desdenhoso em relação às condutas e aos gostos da multidão; trata-se aqui do conhecido esnobismo cultural. No caso mais sutil, ele se transforma em uma moderada e caprichosa modalidade de cinismo, em um divertido ceticismo que, por nada neste mundo, se deixaria levar por um entusiasmo incomum; esse tipo de conduta culta apresenta uma aparência de maior apelo junto às massas, que raramente se apercebem do desconcertante jogo de sua ironia, mas é uma postura de um distanciamento talvez ainda mais radical do que o puro esnobismo. Algum tipo de distanciamento é, em geral, uma condição sine qua non desse segundo tipo de cultura. Outro dos seus requisitos indispensáveis é um contato íntimo com o passado. As ações e opiniões atuais são, antes de mais nada e acima de tudo, vistas à luz de um passado fixado, de um passado de riquezas e glórias infinitas; apenas como uma reflexão posterior, se alguma houver, são tais ações e opiniões concebidas como instrumentos para a construção de um futuro. Os fantasmas do passado, de preferência do passado remoto, assombram o homem culto a cada passo. Ele responde de modo perturbador ao seu mais leve toque; ele se assusta diante da possibilidade de exercer a sua individualidade como uma agência criativa. Mas talvez o aspecto mais extraordinário do ideal culto seja sua seleção de tesouros específicos do passado, que ele considera serem os mais merecedores de devoção. Essa escolha, que pode parecer bizarra a uma pessoa não envolvida, é normalmente justificada por um número de razões, revestidas às vezes de uma cobertura filosófica, mas pessoas menos empáticas parecem estar inclinadas a ver essas razões como meras racionalizações ad hoc e a dizer que a seleção desses tesouros se deve principalmente aos acasos da história.

Resumindo, esse ideal culto é uma roupagem e uma pose. A roupagem pode envolver a pessoa de modo gracioso, e a pose apresenta por vezes muito charme, mas a roupagem é uma roupa pré-fabricada para tudo isso e a pose pemanece sendo nada mais do que uma pose. Na América, o ideal culto em sua forma clássica essencial é uma planta mais exótica do que nos corredores de Oxford ou Cambridge, de onde foi importado para estas terras rústicas, mas ainda assim encontramos fragmentos e derivativos desse ideal com bastante frequência. O ideal culto abarca muitas formas, das quais a forma clássica de 
Oxford é apenas uma das mais típicas. Existem também paralelos chineses e talmúdicos. Onde quer que o encontremos, ele sempre se revela a nós sob a aparência de uma relíquia espiritual que precisa, a todo custo, ser preservada intata.

O terceiro emprego do termo é o mais difícil de definir e ilustrar satisfatoriamente, talvez porque raramente aqueles que o usam são capazes de nos oferecer uma noção perfeitamente clara do que eles próprios pretendem dizer por cultura. A cultura, nesse terceiro sentido, compartilha com nossa primeira concepção técnica uma ênfase maior nas propriedades espirituais do grupo do que do indivíduo. Com nossa segunda concepção, ela compartilha uma ênfase em fatores selecionados a partir do vasto conjunto do fluxo cultural do etnólogo como algo, num sentido espiritual, intrinsecamente mais valioso, mais característico, mais significativo do que o resto. Não seria correto dizer que essa cultura abarca todos os elementos psicológicos, em contraste com os elementos puramente materiais da civilização, em parte porque a concepção daí resultante abrigaria um vasto número de elementos triviais, em parte porque alguns dos fatores materiais podem muito bem ocupar um lugar decisivo no conjunto cultural.

Limitar o termo, como às vezes se faz, a arte, religião e ciência tem, por sua vez, a desvantagem de uma exclusividade rígida demais. Talvez estejamos mais próximos de nosso objetivo se dissermos que a concepção cultural que estamos agora tentando captar tenha como propósito incluir em um único termo aquelas atitudes gerais, visões da vida e manifestações específicas da civilização que asseguram a um povo específico seu lugar distinto no mundo. A ênfase não é colocada tanto no que um povo faz e acredita quanto no como suas ações e ideias funcionam no todo da vida daquele povo, sobre a significação que estas assumem para ele. Exatamente o mesmo elemento da civilização pode ser um componente vital na cultura de um povo e um fator quase negligenciável na cultura de outro. A presente noção de cultura é capaz de emergir particularmente em conexão com problemas de nacionalidade, na tentativa de encontrar encarnadas no caráter e na civilização de um povo alguma excelência peculiar, alguma força distintiva que seja notavelmente sua. Cultura, nesse sentido, se torna quase sinônimo de "espírito" ou "gênio" de um povo, ainda que não completamente, pois enquanto esses termos usados de modo impreciso referem-se mais a um fundo psicológico, ou pseudopsicológico, de uma civilização nacional, cultura inclui nesse fundo uma série de manifestações concretas que se acredita que lhe sejam peculiarmente sintomáticas. A cultura, então, pode ser sucintamente definida como civilização, desde que incorpore o gênio nacional.

É evidente que, aqui, nos aventuramos em terras peculiarmente perigosas. A suposição corrente de que o assim chamado "gênio" de um povo possa ser em última instância reduzido a certos traços hereditários inerentes de 
natureza biológica e psicológica não se sustenta, em sua maior parte, diante de um exame cuidadoso. Frequentemente, o que se assume como uma característica racial inata transforma-se, ante um estudo mais apurado, na resultante de causas puramente históricas. No decurso de um complexo desenvolvimento histórico, um modo de pensar, um tipo distintivo de reação se estabelece como típico e normal; passa então a servir como um modelo para integrar os novos elementos da civilização. A partir de numerosos exemplos de tais distintos modos de pensar ou tipos de reação um gênio básico é composto. Não há nenhuma necessidade de argumentarmos contra essa concepção de um gênio nacional, desde que este não seja cultuado como um fetiche psicológico irredutível. Os etnólogos evitam generalizações amplas e conceitos vagamente definidos. Consequentemente, tendem a ser mais tímidos quanto a operar com gênios e espíritos nacionais. O chauvinismo dos apologistas nacionais, que vê nos espíritos de seus próprios povos excelências peculiares categoricamente negadas aos habitantes menos abençoados do planeta, justifica amplamente essa timidez dos estudiosos científicos da civilização.

No entanto, aqui - como em tantos outros casos -, o conhecimento exato dos cientistas fica um pouco aquém dos insights mais ingênuos, no entanto mais poderosos, suscitados pela experiência e pela percepção não profissional. Negar ao gênio de um povo uma irredutível significação psicológica e referi-lo ao desenvolvimento histórico específico daquele povo não significa, no fim das contas, negar sua existência por meio da análise. Mantém-se a verdade de que, por toda parte, grandes grupos de pessoas tendem a pensar e a agir em acordo com formas estabelecidas e quase instintivas, que lhes são, em larga medida, peculiares. A pergunta se essas formas, que em suas interrelações constituem o gênio de um povo, podem ser basicamente explicáveis em termos de seu temperamento nativo, de seu desenvolvimento histórico ou de ambos, interessa ao psicólogo social, mas não deve nos preocupar muito aqui. A importância dessa pergunta nem sempre é perceptível. Basta saber que de fato as nacionalidades, usando essa palavra sem implicações políticas, vieram a exibir em pensamentos e ações a marca de um certo molde e que esse molde é discernido de forma mais clara em certos elementos da civilização do que em outros. A cultura específica de uma nacionalidade consiste nesse grupo de elementos de sua civilização que mais enfaticamente exibe aquele molde. Na prática, é por vezes conveniente identificar a cultura nacional com seu gênio.

Um exemplo ou dois antes de encerrarmos essas definições preliminares. Todo esse território que agora estamos tentando atravessar é uma espécie de estufa para o subjetivismo, um campo esplêndido para a difusão de presunções nacionais. Não obstante, há um grande número de consensos internacionais quanto às características culturais mais notáveis de vários povos. Ninguém que já se tenha ocupado, mesmo que apenas superficialmente, com a cultura francesa pode não ter se impressionado pelas qualidades de clareza, sistema- 
tização lúcida, equilíbrio, cuidado na escolha dos meios e bom gosto, que permeiam tantos aspectos da civilização nacional. Essas qualidades têm seu lado negativo. Conhecemos a mecanização excessiva, a timidez ou superficialidade emocional (algo bem diferente de contenção emocional), o exagero nas formas do comportamento à custa do conteúdo, que se revelam em algumas manifestações do espírito francês. Aqueles elementos da civilização francesa que evidenciam de modo característico as qualidades do seu gênio constituem, podemos dizer, no sentido restrito que lhe estamos atribuindo, a cultura da França; ou, para formular a ideia de modo um pouco diferente, a importância cultural de qualquer elemento na civilização francesa está na luz que ele projeta sobre o gênio francês. Desse ponto de vista, podemos fazer uma avaliação cultural de certos traços da civilização francesa, como o formalismo do drama clássico francês, a ênfase nos estudos da língua materna e de seus clássicos na educação francesa, a prevalência do epigrama na vida e nas letras francesas, a inclinação intelectualista tantas vezes conferida aos movimentos estéticos da França, a falta de grandiloquência na música francesa moderna, a ausência relativa do aspecto extático na religião e a forte tendência burocrática na administração francesa. Cada um desses e centenas de outros traços comparáveis poderiam ser prontamente encontrados na civilização da Inglaterra. Sua relativa importância cultural, no entanto, arrisco-me a pensar, é menor na Inglaterra do que na França. Na França, eles parecem estar mais profundamente afinados com a rotinas culturais da sua civilização. Seu estudo possibilitaria algo como uma rápida visão panorâmica do espírito da cultura francesa.

Falemos agora da Rússia, cuja cultura apresenta um molde tão definido quanto o da França. Mencionarei apenas um aspecto, mas, a meu ver, talvez o mais significativo da cultura russa - a tendência do russo de ver e pensar os seres humanos não como representantes de tipos, não como criaturas que parecem estar eternamente vestidos com as roupagens da civilização, mas como seres humanos não cultivados, que existem primeiramente em si e para si mesmos, e apenas secundariamente em prol da civilização. A democracia russa tem como seu propósito fundamental menos a criação de instituições democráticas do que a efetiva liberação da personalidade. Aquilo que o russo realmente é capaz de levar a sério é a humanidade elementar e, em sua visão de mundo, a humanidade elementar impõe-se a cada passo. Ele, portanto, se sente sublimemente à vontade consigo mesmo, com seu vizinho e com Deus. Na verdade, não tenho dúvidas de que o mais extremado dos ateus russos se dê melhor com Deus do que os devotos de outros países, para quem Deus é sempre uma espécie de mistério. Em relação ao seu ambiente, incluindo nesse termo toda a maquinaria da civilização, o russo geralmente alimenta um notável desprezo. A subordinação das dimensões profundas da personalidade a uma instituição não é facilmente aceita por ele como um preço necessário a ser pago pelas bênçãos da civilização. Podemos acompanhar em inumeráveis 
formas essa avassaladora humanidade, essa provocação quase impertinente do verdadeiro eu que está no envólucro da civilização. Nos relacionamentos pessoais, podemos notar a curiosa disposição do russo de ignorar todos os obstáculos institucionais que separam o homem do homem; pelo seu lado negativo, isso envolve por vezes uma irresponsabilidade pessoal que não abriga nenhuma insinceridade. A renúncia de Tolstói não foi nenhum fenômeno isolado, foi um símbolo da profunda indiferença russa em relação ao institucionalismo, aos valores acumulados da civilização. Num sentido espiritual, é fácil para um russo derrubar qualquer manifestação do espírito do institucionalismo; suas verdadeiras lealdades estão em outro lugar. A preocupação russa com a humanidade elementar naturalmente se mostra com mais evidência no domínio da arte, onde a autoexpressão tem rédeas soltas. Nas páginas de Tolstói, Dostoiévski, Turgueniev, Gorki e Tchekhov, a personalidade se insurge em seus momentos mórbidos de relações ambivalentes com o crime, em suas depressões e apatias, em seus entusiasmos e idealismos generosos. Tantos personagens da literatura russa contemplam a vida com um olhar perplexo e cético. "Essa coisa que vocês chamam de civilização - isso é tudo que a vida tem a oferecer?", podemos ouvi-los perguntar uma centena de vezes. Também na música o espírito russo se deleita em desmascarar-se a si mesmo, com os gritos e gestos do ser humano como ser humano. Ele se dirige a nós no acento áspero de Mussorgsky e no desespero quase insuportável de Tchaikovsky. Difícil imaginar a corrente principal da arte russa infectada pelo caruncho do formalismo; esperamos ver algum brilho ou grito humano escapar por trás das grades.

Tenho evitado qualquer tentativa de estabelecer um paralelo entre o espírito da civilização francesa e o espírito da civilização russa, entre a cultura da França e a cultura da Rússia. Paralelos estritos forçam uma ênfase em contrastes. Contentei-me em simplesmente sugerir que, subjacente aos elementos da civilização, que é o campo de pesquisa dos etnólogos e historiadores da cultura, existe uma cultura, cuja interpretação adequada está envolta em dificuldades e que, muitas vezes, é deixada aos literatos.

\section{A CULTURA AUTÊNTICA}

A segunda e a terceira concepção do termo "cultura" são as que desejo estabelecer como a base de nossa cultura autêntica - o pretendente ao trono, cujas demandas pelo reconhecimento vamos avaliar. Podemos aceitar a cultura como o molde característico de uma civilização nacional, enquanto da segunda concepção de cultura - aquela que se refere a um tipo tradicional de refinamento individual - tomamos emprestada a noção da forma ideal. Deixo claro desde já que de modo nenhum pretendo defender a causa de qualquer cultura espe- 
cífica. Seria ocioso celebrar ou acusar qualquer condição fundamental da nossa civilização, celebrar ou acusar qualquer traço na textura do seu gênio. Essas condições e esses traços precisam ser aceitos como básicos. Eles por certo se transformam lentamente, como tudo mais na história da humanidade, mas a transformação radical dos fundamentos não parece necessária para a produção de uma cultura autêntica, independentemente de quão grande possa ser a necessidade de reajustes das suas relações. Em outras palavras, uma cultura autêntica é perfeitamente concebível em qualquer tipo ou estágio de civilização e no molde de qualquer gênio nacional. Podemos concebê-la tão facilmente nos termos de uma sociedade polígama muçulmana ou de uma sociedade indígena norte-americana "primitiva" e não agricultora, quanto nos termos de nossas conhecidas sociedades ocidentais. Por outro lado, o que, por contraste, pode ser chamado de culturas "espúrias" pode ser tão facilmente concebível em condições de esclarecimento generalizado, quanto em condições de relativa ignorância e pobreza.

A cultura autêntica não é, por princípio, alta ou baixa; ela é apenas inerentemente harmoniosa, equilibrada e satisfaz suas próprios requisitos. Ela é a expressão de uma atitude ricamente variada, mas de algum modo unificada e consistente ante a vida, uma atitude que vê a significação de qualquer elemento da civilização em sua relação com todos os outros. Em termos ideais, é uma cultura em que nada é espiritualmente sem significado, e na qual nenhuma parte significativa do funcionamento geral traz consigo um sentido de frustração, ou de esforço inútil e desarmônico. Não é um híbrido espiritual de remendos contraditórios, de compartimentos impermeáveis da consiência que evitam a participação numa síntese harmoniosa. Se a cultura tem necessidade da escravidão, ela francamente o admite; se ela abomina a escravidão, encontrará meios de realizar ajustes econômicos que cancelem a necessidade de seu emprego. Ela não ostenta seus ideais éticos de uma oposião intransigente à escravidão apenas para implementar algo que equivalha a um sistema de escravidão em certas partes de seu mecanismo industrial. Ou, se ela construir templos magníficos, ela o fará porque sente a necessidade de simbolizar em belas construções um impulso religioso vital e profundo; se ela estiver disposta a desfazer-se da religião institucionalizada, estará disposta também a dispensar os prédios da religião institucionalizada. Ela não fica embaraçada quando um apelo direto é feito à sua consciência religiosa, para então reparar a situação doando furtivamente alguns dólares para o sustento de alguma missão africana. Nem educa seus filhos obsessivamente para aquilo que é inútil e sem vitalidade, seja para eles seja para sua própria vida adulta. Tampouco tolera mil outros desajustes espirituais, como os que são patentes ena vida americana atual. Seria um exagero dizer que mesmo os mais puros exemplos já conhecidos de cultura autêntica estiveram livres de desacordos espirituais, da esterilidade dos hábitos sociais que perderam sua vitalidade. Mas as gran- 
des culturas, aquelas que instintivamente sentimos que foram organismos espirituais saudáveis, tal como a cultura ateniense da era de Péricles e, talvez em menor escala, a cultura inglesa do período elizabetano, no mínimo tenderam a essa harmonia. É preciso que fique claramente entendido que esse ideal de uma cultura autêntica não tem nenhuma conexão necesssária com o que chamamos de eficiência. Uma sociedade pode ser admiravelmente eficiente no sentido de que todas as suas atividades sejam cuidadosamente planejadas com referência a fins de máxima utilidade para a sociedade como um todo, pode não tolerar nenhum movimento desnecessário e ainda assim ser um organismo inferior enquanto um portador de cultura. Não basta que os fins das atividades sejam socialmente satisfatórios, que cada membro da comunidade sinta que esteja, de alguma forma obscura, contribuindo com sua pequena parte para a realização de um benefício social. Até aí tudo bem, mas uma cultura autêntica se recusa a ver o indivíduo como uma mera engrenagem, como uma entidade cuja única raison d'être reside na sua subserviência a um propósito coletivo do qual ele não é consciente, ou que tenha apenas uma remota relevância para seus interesses e ambições. As atividades principais do indivíduo devem satisfazer diretamente seus próprios impulsos criativos e emocionais, devem ser sempre algo mais do que apenas meios para um fim. A grande falácia cultural do industrialismo, tal como desenvolvido até os dias de hoje, é que, ao submeter as máquinas aos nossos propósitos, ele não soube como evitar a submissão da grande maioria da humanidade às suas máquinas. A telefonista que dedica suas habilidades durante a maior parte do seu dia à execução de uma rotina técnica, que pode ter eventualmente um alto valor de eficiência, mas que não atende a quaisquer de próprias suas necessidades espirituais, representa um sacrifício assustador à civilização. Como solução para o problema da cultura, ela é um fracasso - quanto maiores seus dotes naturais, pior. É de temer-se que isso não valha apenas para a telefonista, mas para a grande maioria de nós, fornalheiros escravos que alimentam os sacrifícios para demônios que destruiríamos se estes não se apresentassem disfarçados de nossos benfeitores. O índio norte-americano que soluciona seu problema econômico pescando salmão com uma lança e captura coelhos com uma armadilha opera num nível relativamente baixo de civilização, mas ele representa uma solução incomparavelmente mais alta do que nossa telefonista para as questões que a cultura propõe para a economia. Não há aqui nenhuma questão quanto à imediata utilidade e à eficácia direta do esforço econômico, nem quanto aos lamentos sentimentalistas pelo desaparecimento do "homem natural". A pesca de salmão com lança é um tipo de atividade culturalmente mais alto do que o da telefonista ou do operário de uma fábrica, simplesmente porque não há nenhum sentido de frustração espiritual durante sua execução, nenhum sentimento de subserviência a exigências tirânicas, ainda que não plenamente formuladas, porque essa atividade se encontra em 
harmonia com todas as outras atividades do índio, ao invés de destacar-se como uma espécie de remendo vazio representado por um esforço meramente econômico no conjunto da vida. Uma cultura autêntica não pode ser definida como uma soma de fins abstratamente desejáveis, como um mecanismo. Ela deve ser vista como o vigoroso crescimento de uma planta, cuja folhas e galhos mais remotos são organicamente nutridos pela seiva das suas raízes. E esse crescimento não é aqui uma metáfora apenas para o grupo; aplica-se também ao indivíduo. Uma cultura que não se constrói a partir dos interesses e desejos centrais dos seus portadores, que opera a partir dos fins gerais em direção ao indivíduo, é uma cultura exterior. A palavra "exterior", que tantas vezes é instintivamente escolhida para descrever tal cultura, é bem escolhida. A cultura autêntica é interior, ela opera a partir do indivíduo em direção aos fins.

Já vimos que não existe uma correlação necessária entre o desenvolvimento da civilização e a relativa autenticidade da cultura que forma sua essência espiritual. Isso requer alguma explicação adicional. Por desenvolvimento da civilização, referimo-nos ao grau crescente de sofisticação de nossa sociedade e de nossas vidas individuais. Essa progressiva sofisticação é o resultado cumulativo inevitável dos processos seletivos da experiência social, das crescentes complexificações dos nossos inumeráveis tipos de organização, e, sobretudo, do crescente conhecimento sobre nosso ambiente natural e, consequentemente, do nosso domínio prático, para fins econômicos, dos recursos que a natureza ao mesmo tempo concede e oculta de nós. É principalmente a força cumulativa dessa sofisticação que nos dá o sentido daquilo que chamamos de "progresso". Empoleirados nas alturas de um prédio comercial de vinte ou mais andares mais alto do que nossos pais jamais puderam imaginar, sentimo-nos como se estivéssemos conquistando o mundo. Impulsionando nossos corpos pelo espaço a velocidades cada vez maiores, sentimos que estamos avançando. Quando falo de sofisticação, incluo não apenas o avanço intelectual e técnico, mas a maioria das tendências que possibilitam uma existência mais limpa e saudável e, em grande medida, também mais humanitária. É ótimo manter as mãos cuidadosamente limpas, eliminar a varíola e administrar anestésicos. Nossa crescente sofisticação, nossa solicitude cada vez maior em obedecer aos ditames do senso comum, tornam imperativas essas tendências. Seria mero obscurantismo querer impedir seu progresso. Mas não existe ilusão mais estranha - e é uma ilusão que quase todos nós compartilhamos - do que acreditar que, pelo fato de os instrumentos da vida serem hoje mais especializados e refinados do que jamais foram, pelo fato de a técnica viabilizada pela ciência ser mais perfeita do que qualquer coisa que o mundo já conheceu, segue necessariamente que estamos, na mesma medida, alcançando uma harmonia mais profunda com a vida, uma cultura mais profunda e mais satisfatória. É como se acreditássemos que um elaborado cálculo matemático que envolve números de sete ou oito dígitos tivesse que resultar em um número de igual 
grandeza. No entanto, sabemos que um milhão multiplicado por zero resulta em zero, tanto quanto um multiplicado por zero. A verdade é que sofisticação - aquilo que normalmente queremos expressar quando falamos em progresso da civilização - é, a longo prazo, um conceito meramente quantitativo que define as condições externas do crescimento ou declínio da cultura. Estamos certos em ter fé no progresso da civilização. Estamos errados se acreditarmos que a manutenção ou mesmo o avanço da cultura seja uma função desse progresso. Uma leitura dos fatos da etnologia e da história cultural comprovam plenamente que os níveis mais elevados da cultura foram frequentemente alcançados em baixos níveis de sofisticação; e que os níveis mais baixos da cultura foram alcançados nos níveis mais altos de sofisticação. A civilização, como um todo, avança; a cultura vai e vem.

Cada mudança profunda no fluxo da civilização, particularmente cada mudança em suas bases econômicas, tende a provocar uma inquietação e um reajustamento dos valores culturais. Formas culturais antigas, tipos costumeiros de reação, tendem a persistir pela força da inércia. O desajustamento dessas reações habituais a seu novo ambiente civilizacional trazem consigo um tanto de desarmonia espiritual, que os indivíduos mais sensíveis eventualmente sentem como uma fundamental falta de cultura. Por vezes, o desajustamento se autocorrige com grande rapidez; por outras, ele persiste durante gerações, como no caso da América, onde um crônico estado de desajustamento cultural vem, por um longo período, reduzindo muito de nossa vida mais elevada a uma exterioridade estéril. É mais fácil, falando-se em termos gerais, que uma cultura autêntica subsista em um nível mais baixo de civilização; a diferenciação dos indivíduos no que se refere às suas funções sociais e econômicas é tão menor do que em níveis mais altos que há menos perigo de se reduzir o indivíduo a um fragmento ininteligível do organismo social. Como colher os benefícios inegáveis de uma grande diferenciação das funções, sem ao mesmo tempo perder de vista o indivíduo como núcleo dos valores culturais vivos, é o grande e difícil problema de qualquer civilização que rapidamente aumenta seu grau de complexidade. Estamos longe de resolver esse problema na América. Na verdade, podemos duvidar se mais do que uma minoria insignificante esteja ciente da existência desse problema. No entanto, a atual inquietação entre os trabalhadores no mundo inteiro tem como uma de suas raízes mais profundas algum tipo de percepção da falácia cultural da atual forma de industrialismo.

Talvez o etnólogo sensível, que tenha estudado uma civilização aborígene em primeira mão, seja aquele que mais se impressione com a frequente vitalidade da cultura em níveis menos sofisticados. Ele admira a vida plena do participante mediano na civilização de uma típica tribo de índios americanos; a firmeza com que cada parte dessa vida - econômica, social, religiosa e estética - está interligada a um todo significativo e em relação à qual ele é muito 
mais do que um peão passivo; e, sobretudo, o papel modelador, muitas vezes definitivamente criativo, que ele exerce no mecanismo de sua cultura. Quando a integridade política de sua tribo é destruída pelo contato com os brancos, e os antigos valores culturais perdem a atmosfera necessária para manter sua contínua vitalidade, o índio se vê a si mesmo num estado de perplexa vacuidade. Mesmo quando consegue encontrar um compromisso bastante satisfatório com seu novo ambiente, obtendo aquilo que seus benfeitores consideram um grande progresso em direção ao esclarecimento, ele é capaz de reter um desconfortável sentido de perda de um vago e grande bem, um estado de espírito que ele dificilmente conseguiria definir, mas que antes havia lhe assegurado uma coragem e uma alegria que a recente prosperidade jamais conseguiu recuperar para ele. O que aconteceu é que ele foi expelido do caloroso abrigo da cultura e lançado no ar frio da existência fragmentária. O fato verdadeiramente triste a respeito do fim do índio não é o seu extermínio em grande número por doenças, nem mesmo o desprezo ao qual tantas vezes ele é sujeito em sua vida na reserva; é o desaparecimento gradual de culturas autênticas, ainda que estas tenham sido construídas com os materiais de uma ordem inferior de sofisticação.

Não temos nenhum direito de exigir dos níveis superiores de sofisticação que preservem para o indivíduo as suas múltiplas funcões, mas podemos nos perguntar se, como uma compensação, o indivíduo não poderia razoavelmente exigir uma intensificação em valor cultural, mais vitalidade espiritual no exercício das funções que lhe restaram. Se essa opção falhar, deve-se admitir que ele regrediu. A limitação de funções opera principalmente na esfera econômica. É, portanto, imperativo que, se o indivíduo pretende preservar seu valor como ser cultural, que ele encontre compensação nas esferas não econômicas e não utilitárias - sejam elas sociais, religiosas, científicas ou estéticas. Essa noção de compensação desperta nossa atenção para um tema importante, qual seja, o dos fins imediatos e dos fins mais remotos do esforço humano.

Como um mero organismo, a única função do ser humano é existir; em outras palavras, manter-se vivo e propagar sua espécie. Por isso, a obtenção de alimento, roupa e abrigo para ele e os que dele dependem constitui o fim imediato dos seus esforços. Há civilizações, como a dos esquimós, em que a maior parte das energias do homem é consumida para a satisfação desses fins imediatos, em que a maior parte das atividades contribui direta ou indiretamente para a obtenção e para o preparo de comida e materiais para o vestuário e abrigo. Não há, entretanto, praticamente nenhuma civilização na qual pelo menos alguma parte da energia disponível não seja liberada para os fins mais remotos, ainda que, como regra, esses fins mais remotos, por um processo de racionalização, aparentem contribuir para os fins imediatos. (Um ritual mágico, por exemplo, que, se considerado psicologicamente, aparenta liberar e dar 
forma a poderosos elementos estéticos emocionais da nossa natureza, é quase sempre disfarçado com alguma finalidade utilitária rotineira - a caça a coelhos ou a cura de doenças.) Na verdade, há pouquíssimas civilizações "primitivas" que não despendam uma excessivamente grande parte de suas energias na busca desses fins mais remotos, ainda que seja verdade que esses fins mais remotos são quase sempre funcional ou pseudofuncionalmente interligados aos fins imediatos. A arte pela arte pode ser um fato psicológico nesses níveis menos sofisticados; certamente não é um fato cultural.

No nosso próprio nível de civilização, os fins mais remotos tendem a se separar completamente dos fins imediatos e a assumir a forma de uma fuga ou um refúgio espiritual em relação à busca desses últimos. A separação dessas duas classes de fins nunca é, nem nunca poderá ser, absoluta; basta constatar a presença de um poderoso impulso de afastamento de cada um em relação ao outro. É fácil demonstrar esse impulso por meio de exemplos tirados da nossa experiência cotidiana. Enquanto na maioria das civilizações primitivas a dança tende a se constituir em uma atividade ritual associada pelo menos ostensivamente a propósitos de natureza econômica, para nós ela é uma atividade mera e autoconscientemente agradável que não apenas está separada da esfera da realização de fins imediatos, mas tende mesmo a assumir uma posição de hostilidade diante dessa esfera. Numa civilização primitiva, um grande chefe dança como uma atividade rotineira, muitas vezes por se tratar de um privilégio particularmente honroso. Em nosso meio, o capitão de indústria ou se recusa totalmente a dançar ou o faz como concessão um tanto desdenhosa à tirania dos hábitos sociais. Por outro lado, o artista de um Ballet Russe sublimou sua dança a um primoroso instrumento de autoexpressão, conseguiu oferecer a si mesmo uma recompensa cultural adequada, ou mais do que adequada, por sua perda de domínio na esfera dos fins diretos. O capitão de indústria pertence à classe relativamente pequena de indivíduos que herdou, numa forma extremamente complicada, um pouco do sentido de controle sobre a obtenção de fins diretos que, por direito cultural, pertence ao homem primitivo; o bailarino resgatou e intensificou para si mesmo o sentimento de participação e criatividade espontânea no mundo dos fins indiretos que, por direito cultural, também pertence ao homem primitivo. Cada um resgatou para si mesmo uma parte dos escombros de uma cultura submersa.

A psicologia dos fins diretos e indiretos sofre uma modificação gradual, apenas parcialmente consumada até agora, nos níveis mais altos da civilização. Os fins imediatos continuam a exercer a mesma influência tirânica sobre a ordenação das nossas vidas, mas ao passo que nossos eus (selves) espirituais se tornam mais ricos e desenvolvem um desejo cada vez mais imoderado por formas mais sutis de experiência, desenvolve-se também uma atitude de impaciência em relação à solução dos problemas mais imediatos da vida. Em outras palavras, os fins imediatos deixam de ser percebidos como fins princi- 
pais e aos poucos se transformam em meios necessários, mas apenas meios para a realização dos fins mais remotos. Esses fins mais remotos, por sua vez, que já não são mais vistos como atividades puramente incidentais que resultam do transbordamento de uma energia concentrada quase que completamente na realização dos fins imediatos, se transformam nos fins principais da vida. Essa mudança de atitude se insinua na afirmação de que a arte, a ciência e a religião de uma civilização mais elevada expressam da melhor maneira seu espírito ou cultura. A transformação de fins brevemente esboçada aqui está longe de ser um fato consumado; antes, é uma tendência obscura na história dos valores, uma expressão da escolha por parte dos participantes mais sensíveis em nossa cultura. Certos temperamentos se sentem impelidos a seguirem essa tendência, outros ficam para trás.

A transformação de fins é da maior importância cultural porque age como poderosa força em prol da preservação da cultura em níveis em que um funcionamento econômico fragmentário do indivíduo é inevitável. Enquanto o indivíduo preserva um sentimento de controle sobre os maiores bens da vida, ele é capaz de assumir seu lugar no patrimônio cultural do seu povo. Agora que os maiores bens da vida se deslocaram em tão grande medida da esfera dos fins imediatos para a esfera dos fins remotos, torna-se uma necessidade cultural para todos aqueles que não querem ser vistos como deserdados a participação na busca desses fins mais remotos. Nenhuma harmonia ou profundidade de vida, nenhuma cultura é possível quando a atividade é praticamente circunscrita pela esfera dos fins imediatos e quando o funcionamento dentro dessa esfera é tão fragmentário ao ponto de não apresentar nenhuma inteligibilidade ou interesse inerentes. Essa é a ironia mais soturna da nossa civilização americana atual. A maioria de nós, privada de qualquer participação - fora uma participação insignificante e culturalmente abortiva - na satisfação dos desejos imediatos da humanidade, é privada também tanto da oportunidade quanto do estímulo de participar da produção de valores não utilitários. Durante parte do tempo, somos animais de tração; durante o resto do tempo, somos consumidores apáticos de bens que não receberam nenhuma marca da nossa personalidade. Em outras palavras, nossos eus (selves) espirituais seguem em sua maior parte famintos e durante praticamente o tempo todo.

\section{O INDIVÍDUO CULTO E O GRUPO CULTURAL}

Não existe oposição real, no fim das contas, entre o conceito de uma cultura do grupo e o conceito de uma cultura individual. Os dois são interdependentes. Uma cultura nacional saudável nunca é uma herança passivamente aceita do passado, mas implica a participação criativa dos membros da comunidade; implica, em outras palavras, a presença de indivíduos cultos. Uma perpetuação 
automática de valores padronizados, que não são sujeitos à remodelação constante por indivíduos dispostos a investir alguma parte de si mesmos nas formas que receberam de seus predecessores, leva à dominância de fórmulas impessoais. O indivíduo fica de fora; a cultura se torna um formalismo, em vez de uma forma de vida, ela deixa de ser autêntica. No entanto, é também verdade que o indivíduo fica desamparado sem um patrimônio cultural sobre o qual possa trabalhar. Ele não pode, a partir de seus poderes espirituais isolados, tecer um forte instinto da trama cultural apenas com o fluxo de sua própria personalidade. Criar significa submeter a forma a uma vontade, não fabricar uma forma ex-nihilo. Se o continuador passivo de uma tradição nos oferece meramente uma etiqueta, a concha onde já não há mais vida, o criador que emerge das sobras culturais oferece-nos pouco mais que um gesto ou um grito, uma promessa estritente de uma visão evocada por nossos desejos.

Há uma curiosa noção, segundo a qual países "novos" são um solo especialmente fértil para a formação de uma cultura viril. "Novo" quer dizer algo antigo que foi transplantado para um meio ambiente desprovido de associações históricas. Seria notável se uma planta, que floresce em calcário negro, de repente adquirisse um novo vigor ao ser transplantada para um chão raso e arenoso. Metáforas são coisas perigosas que não demonstram nada, mas a experiência sugere que essa metáfora é pertinente. Na verdade, não existe nada mais tênue, nada mais ostensivamente imitativo e exterior, nada menos viril e autocomplacente do que as culturas dos assim chamados "países novos". Os ambientes dessas culturas transplantadas são novos, mas as culturas em si são antigas e com aquela idade doentia resultante do seu desenvolvimento interrompido. Se os sinais de um florescimento autêntico de cultura estão tardiamente aparecendo na América, não é porque a América ainda seja nova; antes, a América está atingindo a maturidade, começando a se sentir um pouco velha. Num país genuinamente novo, a preocupação com os fins imediatos da existência reduz a um mínimo a criatividade na esfera dos fins mais remotos. O resultado final é um perceptível acanhamento da cultura. O antigo estoque de bens culturais não materiais persiste sem ser submetido a remodelações vitais, torna-se progressivamente empobrecido, e termina tão desesperadamente desajustado ao ambiente econômico e social que os espíritos mais sensíveis tendem a romper com ele e a recomeçar com o franco reconhecimento de novas condições. Esses recomeços são, invariavelmente, rudes; eles demoram a dar os frutos de uma cultura autêntica.

É apenas um paradoxo aparente o fato de que as mais sutis e mais decisivas influências culturais da personalidade, as mais frutíferas revoltas, sejam discerníveis naqueles ambientes que, longa e ininterruptamente, sustentaram um rico fluxo de cultura. Desse modo, longe de ser sufocado em uma atmosfera de infinitos precedentes, o espírito criativo ganha sustento e vigor por meio de seu próprio desdobramento e, se for suficientemente forte, pode se 
libertar dessa atmosfera com uma postura inimaginável para os tímidos iconoclastas de culturas informes. Não podemos entender de outro modo a história cultural da Europa moderna. Apenas num solo maduro e ricamente diferenciado poderiam surgir os iconoclasmos e as visões de um Anatole France, de um Nietzsche, de um Ibsen ou de um Tolstói. Na América, pelo menos na América de ontem, esses iconoclasmos e essas visões teriam sido ou sufocados no berço ou, se tivessem encontrado ar para respirar, teriam se desenvolvido precariamente em isolamento rude e patético. Não existe incorporação individual saudável e vigorosa de um ideal cultural sem o solo de uma cultura comunal autêntica; e não existe cultura comunal autêntica sem as energias transformadoras de personalidades ao mesmo tempo robustas e impregnadas dos valores culturais do seu tempo e lugar. O mais elevado tipo de cultura vê-se então sob o peso de uma interminável corrente, que, para ser produzida, exigiu trabalho exaustivo e prolongado. Uma cultura como essa evita os dois extremos de "exterioridade" - a exterioridade do excesso, que esmaga o indivíduo, e a exterioridade da aridez. A primeira é a decomposição do formalismo, no qual o indivíduo já não mais é; a segunda, a combinação de imaturidade e decomposição de uma cultura desarraigada, na qual o indivíduo ainda não veio a ser. Ambos os tipos de exterioridade podem ser combinados na mesma cultura, frequentemente na mesma pessoa. Assim, não é incomum encontrar na América um indivíduo que enxertou numa cultura árida e puramente utilitária uma tradição cultural que imita uma elegância já embalsamada. Supõe-se que essa justaposição de atmosferas incongruentes seja mesmo típica em certos círculos.

Olhemos mais de perto o lugar do indivíduo em uma cultura sofisticada moderna. Tenho insistido que uma cultura autêntica é aquela que confere a seus portadores um senso de satisfação interior, um sentimento de mestria espiritual. Nos níveis mais elevados de civilização, esse sentimento de mestria foi, como já vimos, praticamente eliminado da esfera econômica. Ele precisa, portanto, em medida ainda maior do que em civilizações mais primitivas, alimentar-se das esferas não econômicas da atividade humana. O indivíduo é incentivado, ou deveria ser, se fosse verdadeiramente culto, a identificar-se com o amplo segmento de interesses não econômicos. Do ponto de vista adotado neste estudo, isso não significa que a identificação seja um processo puramente casual ou aquisitivo; na verdade, ela se realiza não tanto em função de si mesma quanto para munir o eu (self) com os recursos necessários para desenvolver seus poderes. Em termos concretos, isso significaria, por exemplo, que uma pessoa medíocre, moderadamente talentosa, com habilidade para expressar seus instintos estéticos de forma plástica, e exercendo esse dom ao seu modo sincero e humilde (em detrimento, talvez, de praticamente todos os outros interesses), é ipso facto um indivíduo mais culto do que uma pessoa com dons brilhantes que, de forma geral, se familiarizou com tudo o que há de 
"melhor" do que já foi pensado, sentido e realizado, mas que nunca conseguiu estabelecer uma relação direta entre qualquer segmento do seu leque de interesses e seu eu (self) volitivo, o santuário mais íntimo da sua personalidade. Chamamos um indivíduo deste tipo, por mais brilhante que seja, de "superficial" (flat). Uma pessoa superficial não pode ser verdadeiramente culta. Ela pode, é claro, ser muito culta no sentido convencional da palavra "cultura", mas isso é uma outra história. De forma alguma estou dizendo que a criatividade direta seja essencial, ainda que seja altamente desejável, para o desenvolvimento da cultura individual. Em larga medida, é possível adquirir um senso da mestria exigida ao vincular-se a própria personalidade com a personalidade das grandes mentes e corações que a sociedade reconheceu como seus criadores significativos. É possível, digo, na medida em que esse vínculo, essa experiência vicária, venha acompanhada por alguma porção do esforço, da busca obsessiva pela realização, que é inseparável de todo esforço criativo. Temo, no entanto, que a autodisciplina aqui exigida não é praticada com frequência. $\mathrm{O}$ vínculo, como o tenho chamado, do eu (self) com a alma mestre muitas vezes se corrompe em uma servidão agradável, em uma renúncia superficial da própria individualidade, que é mais insidiosa quanto mais for aprovada pelo julgamento habitual. A servidão agradável pode degenerar ainda mais e transformar-se em vício. Aqueles entre nós que não são de todo cegos reconhecem em alguns amigos, talvez até em nós mesmos, uma complacência com bens estéticos ou científicos que é estritamente comparável com o abuso de substâncias alcoólicas. Ambos os tipos de hábitos de autonegação e autossubmersão são sinais de uma personalidade debilitada; ambos são antitéticos à formação de cultura.

O eu individual, ao aspirar à cultura, se agarra aos bens culturais acumulados da sua sociedade, nem tanto pelo prazer passivo de sua aquisição, mas pelo estímulo que é fornecido à personalidade em desenvolvimento e pela orientação resultante no mundo (ou melhor, num mundo) de valores culturais. A orientação, por mais convencional que seja, é necessária apenas para dar ao eu um modus vivendi com a sociedade como um todo. O indivíduo precisa assimilar grande parte do contexto cultural da sua sociedade, muitos dos sentimentos atuais do seu povo, a fim de evitar que sua autoexpressão degenere em esterilidade social. Um eremita espiritual pode ser autenticamente culto, mas dificilmente ele o será socialmente. Dizer que a cultura individual precisa brotar organicamente do rico solo da cultura comunal não significa dizer que precise ficar amarrada para sempre a essa cultura pelas andadeiras da sua própria infância. Uma vez que o eu individual tenha adquirido força suficiente para andar pela trilha iluminada pela própria luz, ele não só pode como também deve dispensar o andaime que o ajudou a fazer a escalada. Não há nada mais patético do que a insistência com que bem intencionados candidatos à cultura tentam manter ou reviver estímulos culturais que há muito per- 
deram sua importância para o crescimento da personalidade. Atualizar ou reciclar os conhecimentos do grego, por exemplo, nos numerosos casos em que o grego deixou de ter uma relação autêntica com as necessidades do espírito, é quase um crime espiritual. Significa ser mesquinho com a própria alma. Se a jornada pelo caminho da iluminação do eu (self) leva a uma posição que é destrutiva para os próprios valores que alimentaram o eu (self), como aconteceu, se bem que de maneiras muito diferentes, com Nietzsche e Tolstói, não se perdeu de forma alguma o contato com a cultura autêntica. É bem possível, ao contrário, que tenha alcançado seu próprio ponto mais alto do desenvolvimento cultural. Nietzsche e Tolstói, no entanto, são tipos extremos de personalidade. Não há nenhum perigo de que o grande exército da humanidade culta jamais venha a ocupar posições espirituais de tamanho rigor e originalidade. O perigo real, abundantemente comprovado pela experiência cotidiana, está em sucumbir às impiedosas forças niveladoras de uma herança cultural comum e à ação de mentes medianas sobre mentes medianas. Essas forças tenderão sempre a uma padronização geral, tanto do conteúdo quanto do espírito da cultura e, na verdade, tão poderosamente que o efeito centrífugo de personalidades robustas e independentes não precisa ser temido. O zelo em conformar-se à tradição, que os defensores da cultura tantas vezes se sentem impelidos a anunciar, é algo que normalmente podemos dispensar. É, antes, o zelo contrário, o zelo em conformar-se à natureza essencial da própria personalidade, que precisa ser encorajado. Ele precisa ser encorajado como um possível antídoto contra a superficial e tediosa mesmice da perspectiva espiritual, o anêmico faz-de-conta, a presunçosa intolerância dos que desafiam, e que tanto aprisionam nossas almas americanas.

Não há maior teste que possa ser aplicado à cultura individual e comunal do que a atitude assumida em relação ao passado, suas instituições, seus tesouros de arte e pensamento. O indivíduo ou a sociedade autenticamente culta não rejeita desdenhosamente o passado. Eles honram as obras do passado, mas não porque são preciosidades do acaso histórico, não porque, por estarem além do nosso alcance, devam ser vistos através dos vidros sacralizadores de vitrines de museus. Essas obras do passado ainda despertam nossa simpatia e nosso interesse sinceros porque podem, e apenas na medida em que podem, ser reconhecidas como a expressão de um espírito humano que tem afinidades sensíveis com o nosso, apesar das diferenças na expressão exterior. Isso é quase equivalente a dizer que o passado é de interesse cultural apenas quando ele ainda é presente ou pode se tornar futuro. Por mais paradoxal que pareça, o espírito histórico tem sempre sido algo como uma força anticultural, tem sempre agido em alguma medida como um inibidor involuntário da utilizaçao cultural do passado. O espírito histórico diz: "Cuidado, esses pensamentos e sentimentos que você pretende encarnar tão apressadamente no fundamento do seu próprio espírito - eles são de outro tempo e de outro 
lugar e são expressão de motivos alheios. Ao curvar-se sobre eles, você os obscurece com a sombra do seu próprio espírito." Essa fria reserva é uma postura excelente para quem se ocupa com a ciência histórica; sua utilidade para a construção de cultura no presente é duvidosa. Sabemos hoje muito mais sobre a Antiguidade helênica do que os estudiosos e artistas do Renascimento; seria tolice fingir que nosso aproveitamento do espírito helênico, apesar do nosso conhecimento preciso, é comparável à inspiração, ao estímulo criativo que os homens do Renascimento extraíram da sua tradição fragmentária e confusa. É difícil imaginar um renascimento tão próspero quanto aquele na atmosfera crítica de hoje. Caminharíamos com tanta cautela nas trilhas do passado, temendo tropeçar em anacronismos, que, desgastados de tanto cansaço, finalmente cairíamos num sono profundo, a fim de sermos acordados apenas pelo barulho insistente do presente. É possível que, no nosso presente estado de sofisticação, esse espírito de crítica, de distanciamento, seja não apenas inevitável, mas também essencial para a preservação das nossas próprias individualidades. O passado agora é mais passado do que nunca. Talvez devêssemos esperar menos dele do que antes. Ou talvez esperar apenas que ele mantenha seus portões abertos, para que possamos entrar nele e o despojarmos dos elementos que escolhermos para nossos belos mosaicos. Será que o senso crítico em relação à história, que galvaniza o passado para a vida científica, está destinado a matá-lo para a vida da cultura? É mais provável que o que esteja acontecendo é que as correntes espirituais de hoje estejam correndo tão rapidamente, de modo tão turbulento, que temos dificuldades em elaborar uma perspectiva culturalmente vital do passado, que assim é, por enquanto, abandonado como uma múmia glorificada nas mãos dos especialistas. E, por enquanto, nós outros, que não entendemos nossa cultura nem como conhecimento, nem como etiqueta, mas como vida, não perguntaremos sobre o passado "o quê?", nem "quando?", nem "onde?", mas sim "como?" e a ênfase desse "como" será modulada de acordo com as necessidades do espírito de cada um, de um espírito que é livre para glorificar, transformar e rejeitar.

Resumindo o lugar do indivíduo na nossa teoria da cultura, podemos dizer que a busca pela cultura autêntica implica dois tipos de reconciliação. O eu busca instintivamente a mestria. No processo de adquirir um senso de mestria que não seja rude, mas proporcional ao grau de sofisticação próprio de nossos tempos, o eu é compelido a sofrer uma abreviação e a passar por uma modulação. A extrema diferenciação de funções que o progresso do homem impôs ao indivíduo ameaça o espírito; não temos outra escolha senão a de nos submetermos graciosamente a essa abreviação das nossas atividades, mas não podemos permitir que ela corte indevidamente as asas do espírito. Essa é a primeira e mais importante reconciliação - encontrar um mundo pleno de satisfações espirituais nos limites estritos de uma atividade econômica involuntariamente confinada. O eu deve posicionar-se a si mesmo em um ponto 
em que ele possa, se não abraçar toda a vida espiritual do seu grupo, pelo menos captar suficientemente seus raios para que se transformem em luz e chama. Além do mais, o eu deve aprender a reconciliar suas próprias ambições, suas próprias necessidades com a vida espiritual geral da comunidade. Ele deve se contentar em obter da consciência espiritual daquela comunidade e do seu passado apoio não apenas para adquirir os recursos para crescer, mas para desenvolver-se onde seu poder, grande ou pequeno, possa vir a ter um efeito sobre uma vida espiritual que seja de interesse íntimo para as outras mentes. Ainda assim, a despeito de todas as reconciliações, o eu tem o direito de sentir que esteja se desenvolvendo na forma de um crescimento espiritual completo e seguro, cujas justificativas mais fundamentais possam ser encontradas em si mesmo, cujos sacrifícios e compensações devam ser justificados perante si mesmo. A concepção do eu (self) como mero instrumento para a conquista de fins coletivos, seja do Estado ou de outro organismo social, deve ser descartada como algo que, a longo prazo, leva a absurdos psicológicos e à escravidão espiritual. É o eu que concede, se é que deve haver qualquer concessão. A liberdade espiritual, o que dela restou, não é uma esmola concedida, por vezes indiferentemente, por outras com má vontade, pela coletividade. O fato de uma diversa filosofia da relação entre o indivíduo e o grupo ser, no momento, tão dominante, torna mais necessário ainda insistir-se no primado espiritual da alma individual.

É um fato notável que, onde quer que haja uma discussão sobre cultura, a ênfase é instintivamente colocada na arte. Isso vale tanto para a cultura individual quanto para a cultura coletiva. É apenas com reserva que aplicamos o termo "culto" a um indivíduo em cuja vida a dimensão estética não desempenha nenhum papel. Assim também quando queremos captar algo do espírito, do gênio de um período passado ou de uma civilização exótica, voltamos nossa atenção primeira e principalmente para sua arte. Uma análise irrefletida veria nisso nada mais do que a ênfase no belo, no decorativo, que corresponde à noção convencional da cultura como uma vida de refinamento moldada pela tradição. Uma análise mais profunda descarta essa interpretação. Para esta análise, a manifestação mais alta da cultura, a verdadeira quintessência do gênio de uma civilização necessariamente se sustenta na arte, porque a arte é a expressão autêntica, de forma satisfatória, da experiência; da experiência não como algo logicamente ordenado pela ciência, mas como o que nos é direta e intuitivamente apresentado na vida. Como a cultura se apóia essencialmente no desenvolvimento harmonioso do senso de mestria instintivamente buscado por cada alma individual, isso só pode significar que a arte, a forma de consciência na qual a marca do eu é mais direta e menos afetada pela necessidade exterior, é, mais do que todos os outros empreendimentos do espírito humano, destinada a refletir cultura. Relacionar nossas vidas, nossas 
intuições e nossos humores passageiros a formas de expressão que transmitem convicção a outros e nos permitem viver novamente nesses outros é a maior satisfação espiritual que conhecemos, a fusão mais íntima da individualidade com o espírito da sua civilização. Fosse a arte realmente perfeita em sua expressão, ela na verdade seria imortal. Mesmo a maior obra de arte, no entanto, é repleta dos detritos da convencionalidade, das sofisticações peculiares do seu tempo. Ao passo que estas mudam, a natureza direta da expressão de qualquer obra de arte tende a ser crescentemente bloqueada por algo que lhe é imposto de fora, até que este caia gradualmente no esquecimento. Enquanto a arte viver, ela pertencerá à cultura; mas na medida em que adquire a frigidez da morte, ela se transforma em objeto de interesse apenas para o estudo da civilização. Por isso, toda apreciação (e toda produção) da arte tem duas faces. É lamentável que a face voltada para a civilização seja muitas vezes confundida com a face fixada na cultura.

\section{A GEOGRAFIA DA CULTURA}

Uma peculiaridade frequentemente observada do desenvolvimento da cultura é o fato de que ele atinge seus níveis mais altos em grupos relativamente pequenos e autônomos. Na verdade, é de se duvidar que uma cultura autêntica possa pertencer se não a tal grupo restrito, a um grupo entre cujos membros possa se dizer que exista um direto e intenso contato espiritual. Esse contato direto é enriquecido pelo patrimônio cultural comum, do qual se alimentam; ele se torna veloz e germinado por meio de milhares de sentimentos e ideias que são tacitamente assumidos e que constantemente luzem suavemente ao fundo. Tais grupos pequenos e culturalmente autônomos são, por exemplo, a Atenas da era de Péricles, a Roma de Augusto, as cidades-estado independentes da Itália na idade media tardia, a Londres do período elisabetano e a Paris dos últimos três séculos. É usual falar de alguns desses grupos e de suas culturas como se fossem idênticos ou pudessem ser representados por grupos e culturas amplamente extensos. Em uma medida curiosamente grande, tais usos são, na verdade, figuras de linguagem, substituições de uma parte pelo todo. É surpreendente, por exemplo, o quanto da chamada "história da literatura francesa" é, na realidade, a história da atividade literária na cidade de Paris. Sem dúvida, uma cultura estritamente localizada pode propagar sua influência, e constantemente o faz, para muito além da sua esfera propriamente restrita. Às vezes, determina até o ritmo de toda uma nacionalidade, de um vasto império, mas tão somente à custa de sua diluição espiritual, na medida em que se afasta do seu centro de equilíbrio, degenerando em uma atitude imitativa. Se percebêssemos com mais clareza o que a rápida propagação ou 
imposição de uma cultura realmente desencadeia, e em que medida ela conquista destruindo os brotos de um crescimento autônomo mais saudável, estaríamos menos dispostos a aceitar tendências uniformizadoras, menos dispostos a vê-las como progressistas. Uma cultura pode muito bem ser por algo que venha de fora, mas sua suplantação por outra, seja esta superior ou não, não representa nenhum ganho cultural. Se esse processo é acompanhado por ganhos políticos, não nos interessa aqui. É por isso que a tentativa deliberada de impor uma cultura direta e rapidamente, independente da boa vontade que acompanhe tal ação, é uma afronta ao espírito humano. Quando uma tentativa desse tipo é acompanhada não por boa vontade, mas pela brutalidade militar, trata-se do maior crime imaginável contra o espírito humano, é a negação da própria cultura.

Isso significa que devemos abandonar qualquer tendência internacionalista e vegetar para sempre em nossos nacionalismos? Aqui, somos confrontados com a noção errônea de que o internacionalismo se opõe em espírito ao desenvolvimento intensivo de culturas autônomas. O erro surge da falha de reconhecer que o internacionalismo, o nacionalismo e o localismo são formas às quais se podem atribuir conteúdos variados. Não podemos discutir inteligentemente o internacionalismo se não soubermos em que aspectos queremos ser internacionalistas. Infelizmente estamos tão obcecados pela ideia de subordinar todas as formas de associação humana ao Estado e de considerar toda a gama de todos os tipos de atividades como algo que coincide com as fronteiras políticas que fica difícil reconciliar a ideia de uma autonomia de cultura local ou restritamente nacional com uma soberania puramente política e com um internacionalismo político-econômico.

Ninguém consegue prever claramente quais serão os resultados mais importantes dos atuais conflitos mundiais. Talvez se exacerbem e não acalmem as animosidades político-nacionais e tendam, assim, a fortalecer o prestígio do Estado. Mas esse resultado deplorável não deverá ser mais que uma fase passageira. Mesmo agora é evidente que a guerra, em mais de uma maneira, preparou o caminho para um internacionalismo econômico e, por corolário, semipolítico. Todas essas esferas de atividade relacionadas à satisfação de fins imediatos, que, do ponto de vista assumido por nós, nada mais são do que meios, tenderão a se transformar em funções internacionais. No entanto, os processos de internacionalização assumirão formas detalhadas, e no fundo nada mais serão do que o reflexo daquela crescente impaciência do espírito humano em relação à preocupação com fins diretos, dos quais falei mais acima. Esse tipo de problema transnacional, como a distribuição de bens econômicos, o transporte de produtos materiais, o controle das autoestradas, a cunhagem de moedas e inúmeros outros, eventualmente terão que passar às mãos de organizações internacionais pela simples razão de que os homens 
não dedicarão sua lealdade eternamente à inútil administração nacional de funções que são inerentemente de caráter internacional. Na medida em que esse caráter internacional venha a ser plenamente reconhecido, as nossas atuais paixões pelo prestígio nacional na esfera econômica se revelarão como as imbecilidades espirituais que são. Tudo isso tem muito a ver com o eventual desenvolvimento de cultura. Enquanto a cultura é vista como um complemento decorativo de grandes unidades políticas, podemos argumentar plausivelmente que sua preservação depende da manutenção do prestígio dessas unidades. Mas uma cultura autêntica é impensável sem a base de uma consciência espiritual altamente individual; ela raramente preserva sua saúde e sutileza quando é diluída e espalhada sobre uma área de extensão interminável; e em suas esferas mais altas ela não está disposta a se submeter a vínculos econômicos e políticos. Nas atuais circunstâncias, uma cultura internacional generalizada é quase inimaginável. A unidade político-nacional tende a arrogar a cultura para si mesma e, até certo ponto, consegue fazê-lo, mas somente ao preço de um sério empobrecimento cultural de vastas porções do seu território. Se a integridade econômica e política dessas grandes unidades controladas pelo Estado for minada gradualmente pelo crescimento de funções internacionais, sua raison d'être cultural também tenderá a ser enfraquecida. A cultura então tenderá a agarrar-se com intensidade crescente a unidades sociais e políticas relativamente pequenas, unidades que não são grandes demais para incorporar a individualidade, que é, para a cultura, o próprio sopro de vida. Entre esses dois processos, entre a integração das forças econômicas e políticas a uma soberania mundial e a desintegração das nossas desajeitadas unidades culturais atuais em unidades pequenas cuja vida é verdadeiramente vigorosa e individual, o fetiche do Estado atual com sua soberania descontrolada talvez se dissolva num futuro obscuro. O Estado político dos nossos dias há muito se encontra no banco dos réus e foi julgado como insuficiente. As nossas unidades político-nacionais são pequenas demais para a paz e grandes demais para a segurança. Elas são pequenas demais para a solução inteligente dos grandes problemas na esfera dos fins diretos; elas são grandes demais para o enriquecimento frutífero dos fins mais remotos, para a cultura.

É no Mundo Novo, talvez mais do que em qualquer outra parte do planeta, que se manifesta a natureza insatisfatória de uma cultura geograficamente difundida, de pouca profundidade ou individualidade. Encontrar substantivamente as mesmas manifestações culturais, tanto materiais quanto espirituais, muitas vezes até nos mínimos detalhes, em Nova York, em Chicago e São Franciso é entristecedor. Nisso se revela uma superficialidade da própria cultura e uma disposição à imitação em seus portadores que não é encorajadora. Mesmo que no presente não possamos reconhecer nenhum caminho definitivo que nos tire desse pântano cultural superficial, não adianta 
deleitar-se eternamente em autossuficiência. Só podemos nos beneficiar se sondarmos as profundezas dos nossos corações e descobrirmos as suas deficiências. Se exagerarmos nossas fraquezas, não importa; é melhor sermos críticos de nós mesmos do que nos autovangloriarmos. Adquirimos o hábito de reivindicar o mérito por resultados essencialmente quantitativos, que mais se devem a uma natureza extraordinariamente favorável e a um conjunto favorável de condições econômicas do que a qualquer atributo em nós mesmos. Nossas vitórias têm sido brilhantes, mas frequentemente desprovidas de cultura. O nosso hábito de jogar com cartas marcadas conferiu-nos uma atitude perigosa de passividade - perigosa para a cultura. Reclinando-nos opulentamente em nossas poltronas, esperamos que grandes coisas culturais nos aconteçam. Acionamos a maquinaria, e que maquinaria admirável ela é; agora, cabe à cultura se manifestar em sua forte variedade. Os incrementos mínimos da individualidade, que sozinha cria a cultura no eu (self) e aos poucos constrói uma cultura na comunidade, parecem ser, de algum modo, ignorados. Afinal, uma cultura enlatada é tão mais fácil de ser administrada.

No momento, esperamos muito da guerra europeia. Sem dúvida alguma, a guerra e seus efeitos nos arrancarão da nossa soberba e trarão algumas correntes de ar revigorante de influência cultural, mas, se não tivermos cuidado, essas influências logo se enrijecerão em novas padronizações ou se diluirão em mais um estoque de atitudes e reações imitativas. A guerra e seus efeitos não podem ser uma causa cultural suficiente, no melhor dos casos são apenas outro conjunto de condições favoráveis. Não devemos ficar demasiadamente surpresos se uma cultura pericleana não florescer automaticamente. Mais cedo ou mais tarde teremos que assumir a humilde tarefa de explorar as profundezas das nossas consciências e trazer à luz as sinceras partículas de experiência refletida que possamos encontrar. Essas partículas nem sempre serão bonitas, nem sempre serão agradáveis, mas serão autênticas. E então podemos construir. Depois de algum tempo, depois de bastante tempo - pois precisamos ter paciência - uma cultura autêntica - ou melhor, uma série de culturas autônomas vinculadas - agraciarão as nossas vidas. E Nova York, e Chicago, e São Francisco viverão cada uma em sua própria força cultural, e nenhuma ficará olhando para a outra para ver quem está à frente em uma corrida por valores exteriores, mas cada uma estará ignorando serenamente suas rivais porque estará crescendo sobre um solo de valores culturais autênticos. 
Edward Sapir nasce no dia 26 de janeiro de 1884 em Lauenberg, Pomerânia (Prússia), atualmente Lebork, Polônia. Aos cinco anos de idade migra com a família para os Estados Unidos. É aluno de Franz Boas, na Universidade de Columbia, Nova York, sob cuja orientação desenvolve seus primeiros trabalhos na área de Linguística e de Antropologia. Seu reconhecimento internacional, na área de Linguística, tem início com o livro Language, publicado em 1921 e traduzido para diversas línguas. No contexto histórico e intelectual da chamada antropologia boasiana, Sapir destaca-se por uma crítica radical ao evolucionismo, ao difusionismo e ao funcionalismo. Sapir é um antropólogo cuja reflexão sobre a cultura toma como ponto de partida a linguagem. Sua reflexão vem a enfatizar a criatividade individual a partir de determinados padrões culturais, desenhando um projeto científico situado no entrecruzamento da etnologia, da psicanálise e da linguística. Sapir foi professor na Universidade de Chicago entre 1925 e 1931. Em seguida, torna-se professor da Universidade de Yale. Morre em 1939, em New Haven, Connecticut. 


\section{Resumo:}

O artigo discute a noção de cultura e seus diversos usos, elaborando a partir deles uma concepção estruturalmente tensionada pelas categorias autenticidade e inautenticidade. Estas últimas oferecem meios comparativos para o reconhecimento de experiências socioculturais diversas. Numa perspectiva de crítica da cultura, o autor discute o modo pelo qual a inautenticidade distinguiria as modernas sociedades ocidentais, repercutindo a critica modernista da modernidade. O artigo tem como foco de sua crítica a sociedade norte-americana das primeiras décadas do século XX. Ele assinala, no entanto, que autenticidade e inautenticidade não se confundem com determinadas formas mais ou menos evoluídas de vida sociocultural; nem com níveis de desenvolvimento econômico e tecnológico. A inautenticidade não estaria exclusivamente associada à modernidade. As formas de cultura autêntica são pensadas como formas de vida coletiva que passam necessariamente pela experiência individual e passíveis de serem encontradas seja nas chamadas "sociedades primitivas" seja ao longo da história das sociedades ocidentais.

\section{Abstract:}

In this article the author discusses the concept of culture and its several uses drawing on them a structurally tensioned conception based on the ideas of authenticity and spuriousness. Such a conception offers comparative means for the description and analysis of diverse social and cultural experiences. As a cultural critique, the author focuses on the ways cultural spuriousness distinguishes modern Western societies, expressing the modernist criticism of modernity. The focus of the article is the criticism of North American society in the first decades of $20^{\text {th }}$ century. However, he points out that cultural authenticity and spuriousness are not necessarily associated with more or less developed forms of social and cultural life. Neither are they associated with levels of economic and technological development. Cultural spuriousness is not exclusively associated with modernity. He argues that cultural authenticity is present in forms of collective life that necessarily goes through the individual experience and may be found either in the so called primitive societies or along the history of Western societies.
Palavras-chave:

Cultura; Linguagem; Indivíduo; Autenticidade; Crítica da cultura; Modernidade.

\section{Keywords:}

Culture; Language; Individual; Authenticity; Culture Criticism; Modernity. 